\title{
OPTIMIZATION OF MOTION OF AUTOTRANSPORT ON UNEVEN ROADS CONTAINING ASCENDS AND DESCENDS
}

\author{
A. I. Huseynov, \\ Azerbaijan Technical University, Baku, Azerbaijan, azer.h@mail.ru
}

DOI: |0.36724/2664-066X-2020-6-2-27-3|

\begin{abstract}
The impact of roads unevenness, i.e. presence of upward and downward motion zones in the road on auto transport fuel consumption is studied. The task of calculation of optimum interrelation of motion speed and acceleration at the uneven roads in sense of reaching of minimum consumed fuel and minimum emissions on environment is formulated and solved. In the study, an analysis of known works on the topic of research was carried out, which showed that the unevenness of the road, i.e. the presence of descents and ascents on the route is one of the main reasons that led to an increase in fuel consumption by vehicles on the route, while the problem of calculating the optimal functional relationship between the speed and acceleration has not yet been solved. Formulated and solved the problem of finding the optimal relationship between the speed and acceleration of vehicles in terms of achieving the minimum fuel consumption on an uneven track. Practical recommendations have been developed for the implementation of the proposed optimal driving regime on uneven terrain containing descents and ascents.
\end{abstract}

KEYWORDS: auto transport emissions, optimization, speed of motion, acceleration, consumed fuel. 


\section{Experimental research}

Experimental studies carried out using the SMPS installation in Los Angeles to determine the concentration distribution of ultrafine aerosol in the range of particle diameters of 6-220 nm showed that both the total number of aerosol particles and their volume concentration decrease exponentially depending on the distance to motorways [4]. In this case, the normalized amount of aerosol particles decreases as follows

$$
y=\exp (-0.01 x)
$$

where $x$ is the distance to the motorway.

The volume concentration of the same aerosol particles decreases according to the law

$$
y=0.087+1.08 \exp (-0.0093 x)
$$

Graphs of expressions (1) and (2) are shown in Figures 1 and 2.

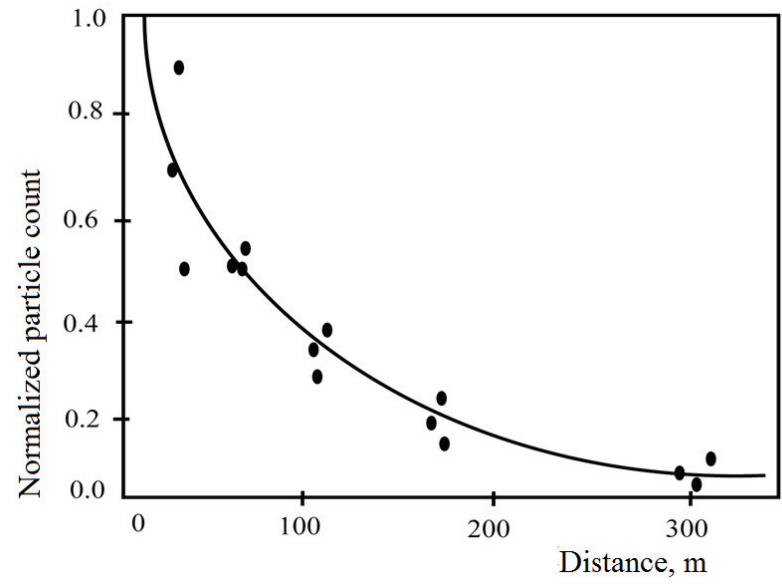

Figure 1. Distribution of the number of aerosol particles with a size of 6-220 nm, depending on the distance to the highway [4]

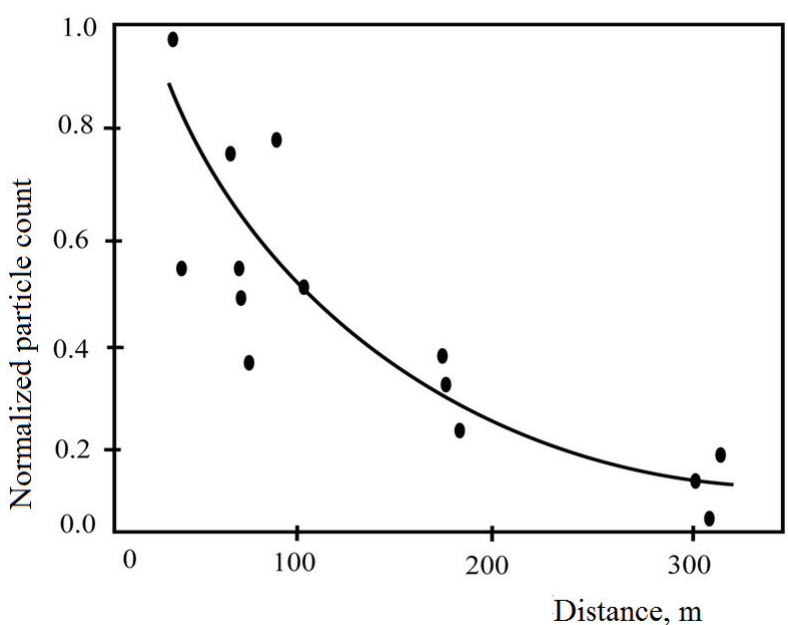

Figure 2. Distribution of the volumetric concentration of aerosol particles with a size of 6-220 nm, depending on the distance to the highway [4]
Experimental studies carried out in New York using the TSI 3039 type FMPS setup made it possible to determine the following distribution laws for the concentration of ultrafine aerosol particles [5]

$$
N_{1}=13138+43242 e^{-D / 123}
$$

during the first week, where $N$ - is the total quantitative concentration (particle $\bullet \mathrm{cm}^{-3}$ ); $D$ - Is the distance in meters, and

$$
N_{2}=32665+22078 e^{-D / 69}
$$

during the second week.

Graphs of expressions (3) and (4) are shown in Figure 3.

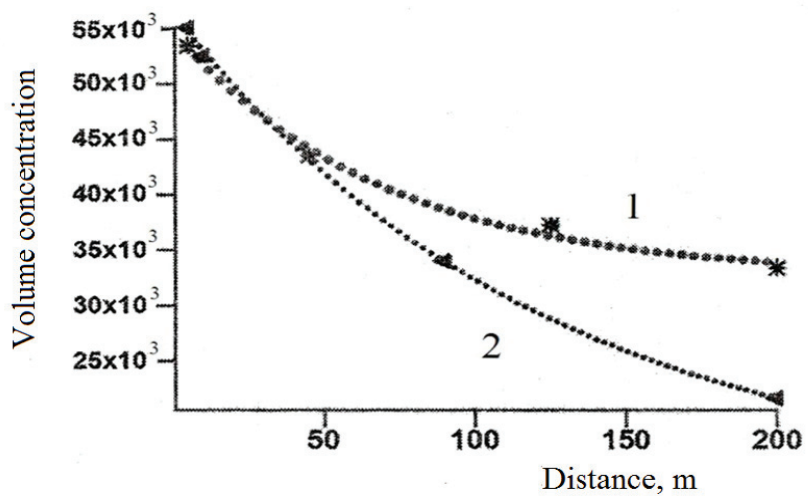

Figure 3. Graphs of the distribution of the volumetric amount of aerosol ultrafine particles depending on the distance to the highway during the first week (1) and the second week (2)

Measurements in Cincinnati, Ohio, USA with MS\&T meters, Air Diagnostics Inc. and OPC, model 1.108; Grimm Technologies Inc. showed that both ultrafine $(10-100 \mathrm{~nm})$ and coarse (1$2.5 \mu \mathrm{m}$ ) aerosol components have an exponential distribution depending on the distance to the highway, however, the attenuation coefficient in the distribution law of coarse aerosol particles is much greater than for fine particles [6]. The corresponding particle distribution plots are shown in Fig. 4.

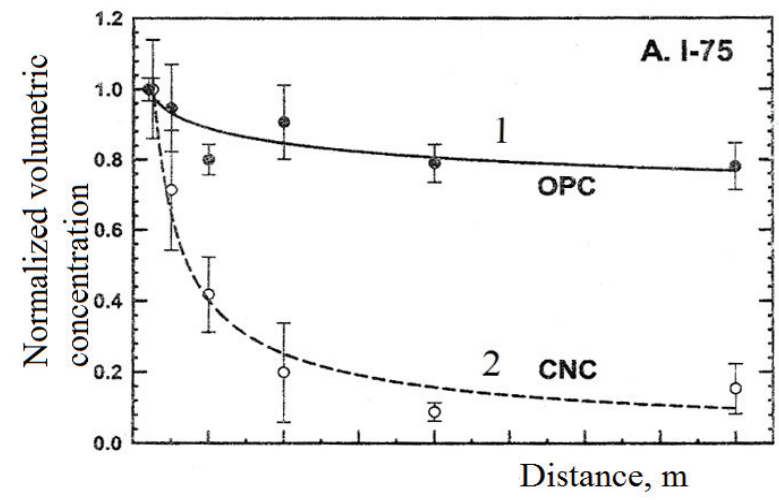

Figure 4. Curves of distribution of the volumetric concentration of aerosol particles depending on the distance to the highway for coarse particles (1) and for ultrafine particles (2) 
The distribution of the volumetric concentration of aerosol near highways has a bimodal character [7]. The first maximum in the zone of particle diameters of $0.01-0.05 \mu \mathrm{m}$ occurs in the range of $0.02-0.03 \mu \mathrm{m}$ due to the rapid cooling of exhaust gases from automobiles [8]. The second maximum in the $0.05-1 \mu \mathrm{m}$ zone occurs in the $0.05-0.3 \mu \mathrm{m}$ range due to incomplete fuel combustion in diesel vehicles [9]. Moreover, the distribution laws of these two fractions of atmospheric aerosol are very different. The fraction in the range of $0.01-0.05 \mu \mathrm{m}$ has an exponential law of rapid decrease in volumetric concentration, while the fraction in the range of $0.05-0.3 \mu \mathrm{m}$ has a slow weakening of the volumetric concentration over distance.

At the same time, aerosol pollution of environment is not the only negative factor in impact of vehicles on environmental life support conditions in urban environment.

One of the most important factors requiring close attention of environment in terms of ensuring life safety of population is the pollution by heavy metals of adjacent to major highways. According to science [10], in accordance with modern ecotoxicological assessments, hazardous heavy metals in the soil form a series

$$
\mathrm{Se}>\mathrm{Ti}>\mathrm{Sb}>\mathrm{Cd}>\mathrm{V}>\mathrm{Hg}>\mathrm{Ni}>\mathrm{Cu}>\mathrm{Cr}>\mathrm{As}>\mathrm{Ba}
$$

This series is very different from the series of hazard of heavy metals, adopted in GOST 17.4.1.02-83, in which the hazard of $\mathrm{Pb}, \mathrm{Zn}$ and $\mathrm{Co}$ in soils is exaggerated, and $\mathrm{V}, \mathrm{Sb}$ and $\mathrm{Ba}$ is underestimated [10].

As a result of measurements with a 210 VGP atomic absorption spectrometer, carried out in the town of Kano, Nigeria, mainly decreasing distribution laws of such types of heavy metals as $\mathrm{Fe}, \mathrm{Pb}, \mathrm{Cu}, \mathrm{Zn}$ and $\mathrm{Cr}$ were obtained [11] (Fig. 5).

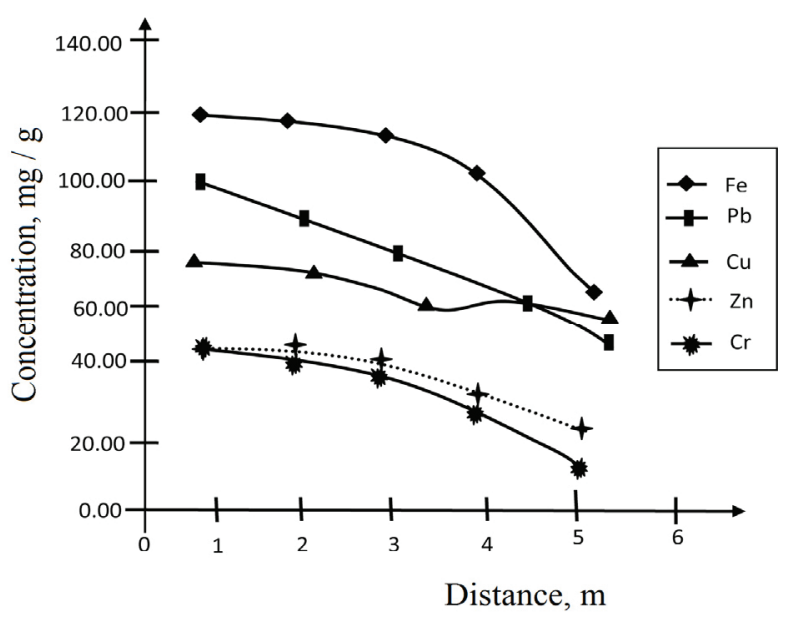

Figure 5. Distribution of hazardous metals concentration in soil depending on the distance to motorway [11]

The condition of the road surface and profile of road have a significant impact on the emission of harmful substances and fuel consumption [1]. Such a close relationship of transport and transport-road structural units leads to the presence of regression relationships between fuel consumption and various indicators of environmental pollution by vehicles. There is the following re- gression relationship between fuel consumption $(x)$ and emissions $\mathrm{CO}_{2}(y)$ [12].

$$
\begin{array}{ll}
y=26,87 x-0,9464 & \text { for gasoline } \\
y=24,173 \quad x-2,1889 & \text { for diesel }
\end{array}
$$

The corresponding graphs of dependencies (5), (6) are shown in Fig. 6 [12].

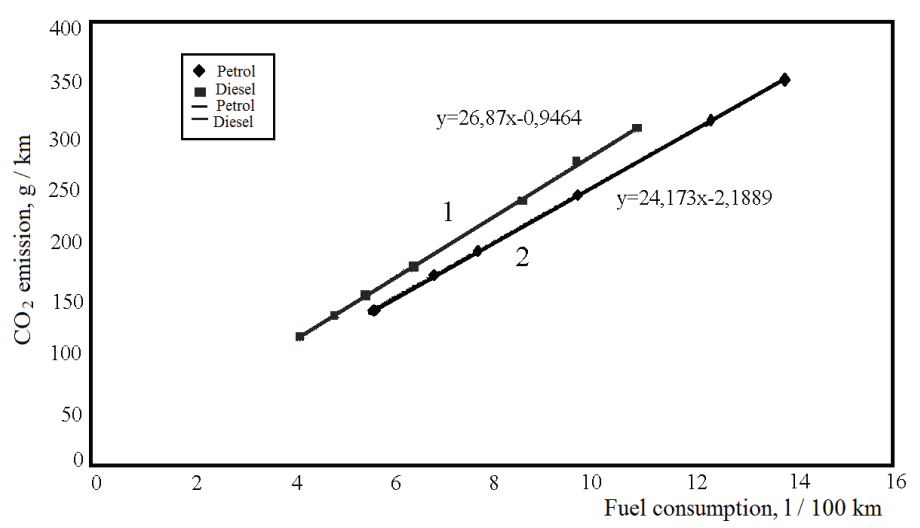

Figure 6. Regression plots of $\mathrm{CO}_{2}$ emission (g / km) on fuel consumption $(1 / 100 \mathrm{~km})$ for a gasoline engine (5) and a diesel engine (6)

At the same time, there is the following statistical relationship between the degree of emission of the $i$-th pollutant (EOi) and the degree of fuel consumption (FR) [13]

$$
\begin{aligned}
& E O_{i}=\lambda+\mu \cdot F R \\
& E O_{i}=E_{i} \cdot F R
\end{aligned}
$$

where $\mathrm{E}$ is the emission index, $\mathrm{g} / \mathrm{sec}$; FR - consumption rate fuel ( $\mathrm{g} / \mathrm{sec}) ; \lambda, \mu=$ const.

Taking into account the above, we can conclude that degree of fuel consumption can be considered as main indicator that determines volume of emitted emissions into the atmosphere. Therefore, in order to determine integrated vehicle emissions in hilly urban areas, it is sufficient to determine the fuel consumption rate at various speeds and accelerations that occur when driving on slopes and inclines. Thus, in this article, the problem is posed of finding the optimal relationship between the driving speed and the acceleration of vehicles with some introduced restrictions in the sense of achieving minimum emissions into the atmosphere when driving on an uneven track containing descents and ascents.

\section{Method for solving the problem}

A similar research task was formulated and solved in a slightly different way in [14]. To develop a new method for solving the problem, we partially use the results of work [14], according 
to which the concept of a system of ecological driving of a car on a track with a descent and an ascent was developed (Fig. 7).

This system uses a vehicle dynamics model; engine fuel consumption model and road surface gradient information. This model generates a control input that maximizes fuel economy on the highway.

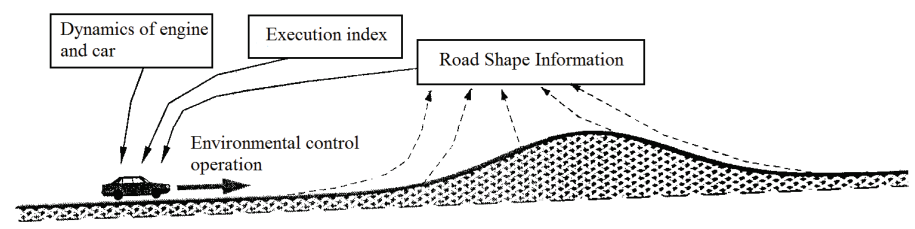

Figure 7. Eco driving system concept using road shape information and model prediction

The fuel consumed by a car at any speed and acceleration can be calculated using the formula [14]:

$$
f_{v}=b_{0}+b_{1} v+b_{2} v^{2}+b_{3} v^{3}+a\left(c_{0}+c_{1} v+c_{2} v^{2}\right)
$$

where $b_{i} ; i=\overline{0,1,2,3} ; C_{i} ; i=\overline{0,1,2} ; a$ - constant values.

In future, a specific research task is formed as follows. In accordance with the proposed car model, it is assumed that in optimal mode there is a unique function

$$
v=v(a)
$$

denoting the assumption that acceleration of the quantity $a$ can be developed only at a speed $v$.

In this case, the restrictive condition is introduced

$$
S_{1}=\int_{-a_{0}}^{a_{0}} F(v(a)) d a=c ; c=\text { const }
$$

where $F$ - any continuous monotone function.

Taking into account expressions (9) and (10), the integral partial functional of the goal can have the form

$f_{u .1}=\int_{-a_{0}}^{a_{0}}\left[b_{0}+b_{1} v(a)+b_{2} v(a)^{2}+b_{3} \cdot v(a)^{3}+a\left(c_{0}+c_{1} v(a)+c_{2} v(a)^{2}\right)\right] d a$

Taking into account expressions (11) and (12), compose the complete functional of unconditional variational optimization

$f_{u, 2}=\int_{-a_{0}}^{a_{0}}\left[b_{0}+b_{1} v(a)+b_{2} v(a)^{2}+b_{3} \cdot v(a)^{3}+a\left(c_{0}+c_{1} v(a)+c_{2} v(a)^{2}\right)\right] d a+\lambda \cdot \int_{-a_{0}}^{a_{0}} F(v(a)) d a$

where $\lambda$ - Lagrange multiplier.

Thus, it is required to find such a function $v(a)$ at which the value $f_{u .2}$ - the integral value of consumed fuel reaches minimum value.

We give an approximate solution to the formed optimization problem in the form of a model study using the model data given in [14].

\section{Model research}

Solving the problem of minimizing expression (13) is equivalent to minimizing the following functional (in what follows, we assume that $F$ is the identity function):

$f_{u, 2.1}=\int_{-a_{0}}^{a_{0}}\left[b_{0}+b_{1} v(a)+b_{2} v(a)^{2}+b_{3} \cdot v(a)^{3}+a\left(c_{0}+c_{1} v(a)+c_{2} v(a)^{2}\right)\right] d a+\lambda \cdot \int_{-a_{0}}^{a_{0}} v(a) d a$

According to [14], constant coefficients $\mathrm{b}$ and $\mathrm{c}$ are defined as $b_{0}=0,1569 ; b_{1}=2,450 \cdot 10^{-2} ; b_{2}=-7,415 \cdot 10^{-4} ; b_{3}=5,975 \cdot 10^{-5}$; $\mathrm{c}_{0}=0,07224 ; \mathrm{c}_{1}=9,681 \cdot 10^{-2} ; \mathrm{c}_{2}=1,075 \cdot 10^{-3}$.

According to Euler's method [15], the optimal function $v(a)_{o p t}$ at which the functional of the goal (14) would reach an extreme value is determined by the condition:

$$
\frac{d\left\{b_{0}+b_{1} v(a)+b_{2} v(a)^{2}+b_{3} v(a)^{3}+a\left(c_{0}+c_{1} v(a)+c_{2} v(a)^{2}\right]+\lambda \cdot v(a)\right\}}{d v(a)}=0
$$

Taking into account condition (15), as well as the above values of the constants $a$ and $b$, obtain

$$
\begin{aligned}
& 2,450 \cdot 10^{-2}-2 \cdot 7,415 \cdot 10^{-4} \cdot v(a)+3 \cdot 5,975 \cdot 10^{-5} \cdot v(a)^{2}+a \cdot 9,681 \cdot 10^{-2}+ \\
& +2 a \cdot 1,075 \cdot 10^{-3} \cdot v(a)+\lambda=0
\end{aligned}
$$

Having performed the necessary calculations, represent expression (16) in the following form

$$
v(a)^{2}+v(a)(12 a-8,3)+13,6+54 a+\lambda=0
$$

Solving the quadratic equation (17) obtain

$$
v_{1,2}(a)=\frac{8,3-12 a}{2} \pm \sqrt{\frac{(8,3-12 a)^{2}}{4}-(13,6+54 a+\lambda)}
$$

In expression (18), one should choose addition, since otherwise, with negative accelerations, negative values of $\mathrm{v}$ (a) can be obtained. Therefore, we have

$$
v(a)=\frac{8,3-12 a}{2}+\sqrt{\frac{(8,3-12 a)^{2}}{4}-(13,6+54 a+\lambda)}
$$

The resulting expression (19) determines the optimal relationship between acceleration and vehicle speed at which emissions to the environment are minimal. 


\section{Discussions}

As can be seen from expression (19), regardless of the sign and magnitude of the Lagrange multiplier $\lambda$, for small a we obtain large $v(a)$ and vice versa. Consequently, to achieve the extreme value of the target functional at high speed, a small positive acceleration must be realized and vice versa. With negative acceleration, everything happens the other way around, i.e. at high speed, a large negative acceleration is required, and at low speed, a small negative acceleration is required.

The extremum of functional (14) turns into a minimum under the condition

$$
2 v(a)>8,3-12 a
$$

Therefore, the above conclusions are valid for

$$
a>\frac{8,3}{12}-\frac{2 v(a)}{12}
$$

for both positive and negative $a$.

Otherwise, these conclusions should be reversed.

As can be seen from the above, the specific value of the Lagrange multiplier $\lambda$ does not affect the obtained qualitative conclusions.

Formally, to calculate the value of $\lambda$, it suffices to write expression (18) into integral (11), carry out the integration, and for a given value $C$ calculate the value $\lambda_{0}$.

\section{Conclusions}

Let's formulate the main conclusions of the study:

1. Analysis of well-known works on the topic of research showed that the unevenness of the road, i.e. the presence of descents and ascents on the highway is one of the main reasons that led to an increase in fuel consumption by vehicles on the highway.

2. Analysis of the known works on calculating the fuel consumed by vehicles on uneven terrain with descents and ascents showed that until now the problem of calculating the optimal functional relationship between the speed of movement and acceleration has not been solved.

3. Formulated and solved the problem of finding the optimal relationship between the speed and acceleration of vehicles in terms of achieving the minimum fuel consumption on an uneven track. Practical recommendations have been developed for the implementation of the proposed optimal driving regime on uneven terrain containing descents and ascents.

\section{References}

1. Erokhov V.I., Bondarenko E.V. Influence factors on traffic exhaust emissions and fuel consumption of vehicles. Messenger $O G U$. No. 4, 2005. P. 139-151.

2. Alessandrini A., Filippi F., Ortenzi F. Consumption calculation of vehicles using OBD data.

3. Baigabulova Zh., Suleimenova K., Bekmagambetova J., Suleimenov I. The ecological and economic methods of analysis of the urban transport system. The international Archives of the Photogrammetry, Remore Sensing Information Sciences. Vol.XXXVII. Part B8. Beijing. 2008.

4. Y. Zhu, W.C. Hinds, S. Kim, C. Sioutas. Concentration and Size Distribution of Ultrafine Particles Near a Major Highway. Journal of the Air \& Waste Management Association. Vol. 52 September 2002. P. 1032-1042.

5. T.H. Whitlow, A. Hall, K.M. Zhang, J. Anguita. Impact of local traffic exclusion on near-road air quality: Findings from the New York City "Summer Streets" campaign. Environmental Pollution 159 (2011). 2016-2027.

6. T. Reponen, S.A. Grinshpun, S. Trakumas, D. Martuzevicius, Z.M.Wang, G.LeMasters, J.E. Lockey, P. Biswas. Concentration gradient patterns of aerosol particles near interstate highways in the Greater Cincinnati airshed. J Environ. Monit., 2003, No. 5. P. 557-562.

7. B. Martinenas, V. Spakauskas. Simulation of traffic pollution dispersion near roadways. Lithuanian Journal of Physics, Vol. 50, No.2, pp. 255-260. 2010. doi:10.3952/lithjphys.50212

8. N. Bukowiecki, J. Dommen, A.S.H. Prevot, R. Richer, E. Weingartner, U. Baltensperger. A mobile pollutant measurement laboratorymeasuring gas phase and aerosol ambient concentrations with high spatial and temporal resolution, Atmos.Environ.36. P. 5569-5579. 2002.

9. U. Baltensperger, N. Streit, E. Weingartner, S. Nyeki, A.S.H. Prevot, R. Van Dingen, A. Virkkula, J.P. Putaud, A. Even, H.ten Brink, A. Blatter, A. Neftel, H.W. Gaggeler, Urban and rural aerosol characterization of summer smog events during the PIPAPO field campaign in Milan, Italy, J.Geophys. Res. 107(D22), 8193. 2002.

10. Vodyanitsky Yu.N. On the hazardous heavy metals/metalloids in soils. Bulletin of Soil Institute V.V. Dokuchaev, 2011. Vol. 68. P. 56-82.

11. J.T. Ayodele, C.D. Oluyomi. Grass contamination by trace metals from road traffic. Journal of Environmental Chemistry and Ecotoxicolgy. Vol.3 (3), pp. 60-67, March 2011.

12. Mickunaitis V., Pikunas A., Mackoit I. Reducing fuel consumption and CO2 emission in motor cars. Transport - 2007, Vol. XXII. No 3. P. $160-163$.

13. Cappiello A., Chabini I., Nam E.K., Lue A., Zeid M.A. A Statistical Model of Emission and Fuel Consumption.

14. Kamal M.A.S., Mukai M., Murata J., Kawabe T. Ecological vehicle control on roads with up-down slopes. Article in IEEE transactions on intelligent transportation systems. October 2011. Impact Factor: 2.38 DOI:10.1109/TITS.2011.2112648 Source: IEEE Xplore.

15. El'sgol'ts L.P. Differential equations and calculus of variations. Moscow: Science, 1979. 340 p. 